\title{
A CO-DESIGN PROTOTYPING APPROACH FOR BUILDING A PRECINCT PLANNING TOOL
}

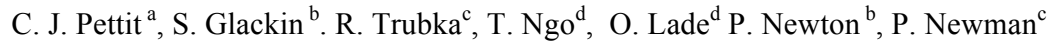 \\ a Architecture Building and Planning, The University of Melbourne, cpettit@unimelb.edu.au \\ b Institute for Social Research, Swinburne University of Technology, sglackin@swin.edu.au, pnewton@swin.edu.au \\ ${ }^{c}$ Curtin University Sustainable Policy Institute, Curtin University rtrubka@crcsi.com.au, P.Newman@curtin.edu.au \\ ${ }^{\mathrm{d}}$ School of Engineering, The University of Melbourne, dtngo@unimelb.edu.au, oliver.lade@unimelb.edu.au
}

Technical Commission II

\begin{abstract}
KEY WORDS: precinct planning, co-design, 3D visualisation, workflows, sustainability assessment, agile software development
\end{abstract}

\begin{abstract}
:
As the world is becoming increasingly urbanized there is a need for more sustainability-oriented planning of our cities. Policy and decision-makers are interested in the use of evidenced based approaches and tools that will support collaborative planning. There are a number of tools in the domain of spatial planning and decision support systems that have been built over the last few decades but the uptake and use of these tools is somewhat limited.
\end{abstract}

In the context of Australia there is significant urban growth occurring across the major cities and a need to provision planners and developers with precinct planning tools to assist in managing infill and the densification of the existing urban fabric in a carbon constrained economy. In this paper we describe the development of a new precinct planning tool known as the Envision Scenario Planner (ESP), which is being applied initially in two cities, Melbourne and Perth to assist in the urban design and planning of Greyfield sites.

To set the scene in this paper we firstly provide a brief review of the existing state of play of visualization and modelling tools available to urban planners in Australia. The focus on the paper will be to introduce an iterative co-design prototyping approach for developing a best practice precinct planning support tool (ESP) from an earlier tool known as ENVISION. The first step of the approach is an exposure workshop with experts to refine the proposed tool workflow and its functionality. Subsequent iterations of the prototype are then exposed to larger audiences for validation and testing. In this paper we will describe the process and the preliminary findings in implementing the first phase of this iterative co-design prototype approach.

\section{INTRODUCTION}

\subsection{Aim and Context}

This paper introduces a co-design prototyping approach that is being used to develop an urban precinct planning tool. In terms of planning, there are 'big-picture' strategic planning of entire cities and planning of much smaller units, often referred to as precincts or neighbourhoods. The precinct planning tool explored in this paper is being developed and tested in the cities of Perth and Melbourne in Australia and builds upon ENVISION, a spatial decision support system for participatory planning in greyfield areas (Glackin, 2013).

There is currently a paucity of widely used evidenced-based tools that support planners in dealing with the infill occurring in many inner and middle suburbs across cities in Australia. Infill (the reutilisation of existing residential land) is critical to slowing the urban sprawl of Australian cities, but it is politically contentious and involves multiple stakeholders (such as local and state government, property developers and local communities), many of whom have conflicting objectives. An urban precinct planning tool capable of being used in real time engagement among any combination of stakeholders to initiate successful neighbourhood change is fundamental to sustainable urban development in the $21^{\text {st }}$ century. This research endeavours to build a precinct planning tool to support the urban design and planning of 'greyfield' sites, namely established areas in the middle suburbs with aging infrastructure and predominately private ownership (Newton et al., 2012; Newton \& Glackin, 2014).

The precinct planning tool is one of a number of online participatory planning and decision support system online tools the Australian Urban Research Infrastructure Network (AURIN) is building. Other such tools include an online agent based walkability tool (Badland et al., 2013), an online version of the ENVISION tool (Newton \& Glackin, 2013) and an online What If? (OWI) participatory planning support system (Pettit et al., 2013).

The AURIN workbench, which consists of such planning support tools and a number of federated data feeds, is based on an open-source federated technical architecture - see Figure 1 (Sinnott et al., 2014). AURIN has been funded by the Australian Government to establish an infrastructure network to support the urban research, policy and decision-making community. AURIN has a number of "Lenses", or themes, to support both discipline-specific and multi-disciplinary research (Pettit et al., 2013). The need for tools to assess and combat unsustainable housing development, combined with the uptake of 3D technology as the most effective way to assess architectural and engineering designs (Seo, Tucker \& Newton), has led the AURIN Innovative Urban Design Lens to mandate a 3D 
precinct urban planning tool. This is not only a necessity to bring existing CAD, BIM and REVIT plans into an analysis engine, but also to provide smaller projects, which do not have the resources for sustainable, social and economic assessment, with the resources to perform analysis quickly and effectively. However, due to vast array of potential projects that such a system would be required to assess, the $3 \mathrm{D}$ precinct planning tool must also adhere to the legislative, economic, design and operability constraints of multiple stakeholders in many contacts and from many development arenas (as covered above).

The optimal solution would see a diverse range of end-users (the majority of whom are not experts) utilising the tool to better plan their localities. As such, and to improve the chances of the tool's uptake by the target groups, a 'co-design' methodology (Sanders \& Stappers, 2008) was utilised, which focuses on the development of 'artefacts' (in this case software interfaces, workflows and outputs) from which user feedback could be acquired to drive development.

The first prototype of the precinct planning tool introduced in this paper is endeavouring to meet this requirement. The codesign prototyping approach has been undertaken for both pragmatic reasons of time and also importantly to ensure the tool is of practical relevance to end users who are focused on the sustainable planning of infill sites across Australian cities.

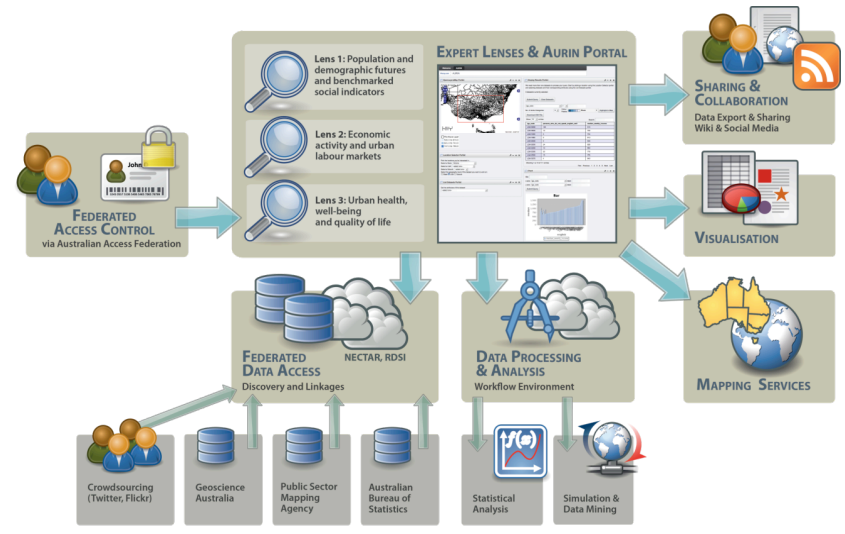

Figure 1: AURIN workbench: an open-source federated technical architecture Source: Sinnott et al. (2014).

\subsection{State of the Art of Precinct Planning Tools}

Newton et al. (2013) recently undertook a comprehensive review of precinct assessment and rating tools in Australia. This study analysed the effectiveness of 12 existing precinct assessment and rating tools in Australia including for example: MUtopia, developed from the University of Melbourne, PrecinX, developed by the NSW Government, Spatial Systems and Integration Model (SSIM) developed by AECOM and the Local area Envisioning and Sustainability scoring system (LESS) developed by Hassell. The analysis of available tools placed an emphasis on the top-down structure of system methodologies - i.e. capturing all carbon related outputs, including lifecycle assessment, resilience, eco-efficiency, cost absorption and human scale metrics. Project outputs conceded that while these tools are based on similar internal logic, their outputs can vary widely, and also, due to the focus on sustainability, and not necessarily carbon or resilience, do not provide the rigour required of a $21^{\text {st }}$ century precinct analysis tool both globally and nationally. The report concluded by noting that precinct assessment is in its infancy and further study, particularly in 'living laboratories' is required to establish a reliable model (Newton et al., 2013).

There are also other precinct planning tools available that are being used to support the visualisation and analysis of urban design scenarios for redevelopment sites. These include the CommunityViz GIS - Planning Support System, which enables scenarios to be constructed and visualised and 2D and 3D and assessed against a number of indicators (Kwartler \& Bernard, 2001). ESRI's CityEngine, which is an ArcGIS extension for the $3 \mathrm{D}$ visualisation of urban scenarios from city scale to precinct scale (http://www.esri.com/software/cityengine) and Synthicity's recently launched Beta product GeoCanvas (http://www.synthicity.com/geocanvas.html).

ENVISION is a GIS-based participatory planning tool (Glackin, 2013). ENVISION was developed to allow both state and local governments to identify potential redevelopment precincts and to better capitalise on the intensification opportunities that exist in the urban 'greyfields'. Based largely on municipal data, this tool allows users to negotiate varying perspectives on the strategic focus of redevelopment and, combined with geographical, market and property data to predict and act on urban change. The Envision Scenario Planning (ESP) Tool outlined in this paper complements ENVISON by providing visualisation, workflows and assessment at the next scale down, within the identified potential redevelopment precincts. Importantly it enables precinct to be visualised and analysed so that end users can more full explore the decision space and understand the impacts of build envelopes, setback, shading and various tree plantings and their aesthetic value.

Based on the results of this review of precincts assessment and rating tools available, the MUtopia tool was selected as the base platform from which to build an online open-source precinct planning tool that will be made accessible to urban researchers, policy and decision-makers who are interested in creating and exploring urban redevelopment scenarios.

\subsection{Approaches to Prototyping Software Development}

The traditional approach to software product development was one of rigorous requirements specification followed by detailed design, implementation and testing in sequence, typically over the course of multiple years. The critical flaw of this software development life cycle methodology in general practice was a severe inflexibility to respond to changes in requirements.

In recent years, both end user needs and competitive products are advancing so rapidly that needing to respond to changing requirements during development is not just likely but certain. The Agile software development movement (Beck et al., 2001) is a response from practitioners to address this issue, among others. Agile development requires frequent end user feedback to drive short-term prioritisation of features and to correct misinterpretations and inadequate specifications as they arise, yielding a more robust and iterative development process. The Agile software development aligns well with the co-design methodology used to elicit end user feedback. Hence, the agile software development approach was selected to support the Codesign prototyping approach in developing the ESP precinct planning tool. 


\section{METHODS}

The co-design prototyping approach is driven by user requirements as illustrated in Figure 2. User requirements were determined through a number of workshops and semi-structured interviews, which are discussed in the next sub-section of the paper. The user requirements are obtained through the co-design prototyping approach where the software is then developed over a period of 3-4 months. The results of the prototype version of the tools are then presented back to end users for further feedback on functionality and usability of the tool.

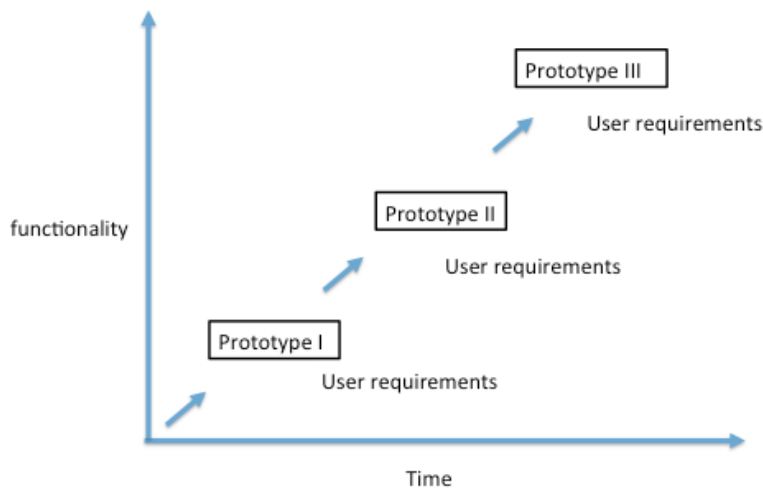

Figure 2: Co-design Prototyping Approach for 3D Precinct Planning Tool Development.

\subsection{Workshops \& Interviews}

In order to determine the system requirements of the ESP precinct planning tool, and based on its multi-disciplinary nature, end-user workshops were held in the two locations that the system would initially service: Perth and Melbourne. Both workshops occurred in March 2014 and were a response to a lack of consensus in the project of how the system should look and operate. Hosted jointly by Curtin University (Western Australia) and The University of Melbourne (Victoria), the aim of these workshops was to determine the look and feel of the system (in terms of visualisation interface and data access), the inputs and outputs that were most significant to a cross section of end users, and the level of detail required, particularly relating to the housing typologies that the system would host. Workshop attendees consisted of statutory and strategic planners from local governments, property developers, academic experts (in sustainability, water, carbon, software design and precinct analysis), landscape architects, data custodians and representatives from state government.

Workshops began with an overview of precinct scale, 'greyfield' redevelopment and a demonstration of the prototype system. The prototype demonstrated basic functionality, such as navigation in a $3 \mathrm{D}$ virtual globe, visualisation of precinct objects in the form of basic extruded coloured blocks, and a few feedback visuals in the form of bar charts and graphs depicting energy use, occupancy and the like (Figure 3).

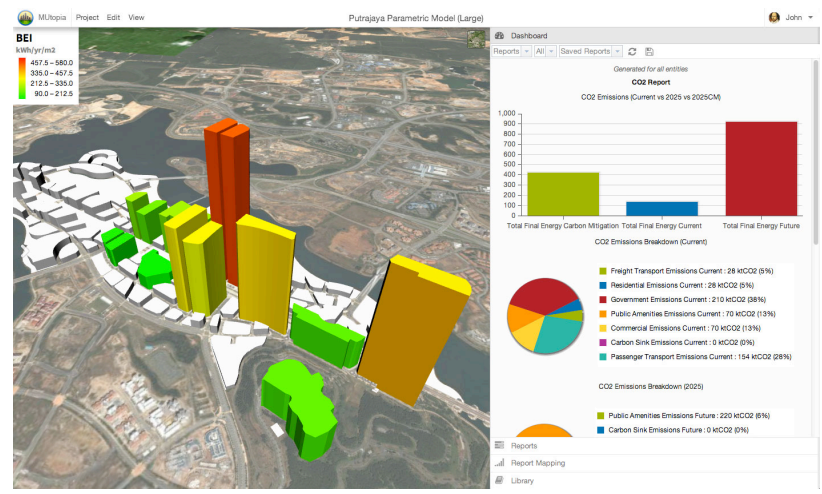

Figure 3: Prototype 3D Precinct Planning tool reporting capabilities.

The intention of the initial prototype demonstration was to stimulate ideas and provide a platform for discussing the potential of existing technology. Attendees were then presented a proposed system workflow with screenshots depicting how an infill site might be redesigned and populated with new precinct objects. After this, attendees were asked, in groups of three to four, to discuss the proposed workflow, the potential workflow alternatives and the level of visual detail required in the precinct objects. Each group in turn then presented the salient points that were discussed, which led to general discussion on the topic at hand.

Next, a brief presentation was given on a series of proposed housing typologies for inclusion in the ESP precinct planning tool. The typologies consisted of floor plans, sub-assemblies, building materials and fit-out items (such as appliances, lighting, solar photovoltaic (PV), etc.) that could be used to evaluate and assess a precinct's performance. This was followed again by group discussions and presentations before moving onto the final topic: assessment criteria. A final presentation was delivered that covered the state-of-the-art of precinct assessment in Australia along with a table of all the assessment factors and metrics that could be employed in ESP. Feedback was then received from the groups on assessment criteria, the assessment priorities and the geographic and temporal scope in which assessment criteria should be reported. The workshops were concluded by general discussion among all the attendees. Notes recorded by each of the groups and voice recordings captured during the workshops were later transcribed, tabulated and coded into themes. This data was then collated and presented back to attendees and researchers for validation.

The inquiry methodology broadly followed a Participatory Action Research (Liamputtong \& Ezzy, 2005) and Grounded Theory Approach (Strauss and Corbin 1988), where participant responses both drive and validate future development. Due to the significance of capturing user feedback, these research methodologies work well with the Co-Design prototype approach for software development - combining rigorous qualitative social inquiry methodologies with development and analysis of the toolkits and prototypes required for design innovation and acceptance (see the generative and evaluative stages of figure 4). 


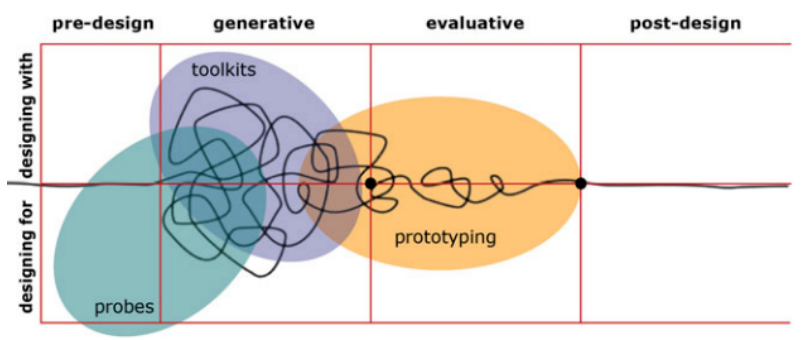

Figure 4: Co-Design research framework (Sanders and Stappers 2014, p.11)

From Figure 4, the 'predesign' stage of development largely rested on the prior research and expertise of the research team, in terms of their experience developing visualisation tools, their interaction with key stakeholders (Newton and Glackin 2013) and their significant experience in community engagement for urban redevelopment (Murray et al. 2014). The culmination of this, combined with significant exploration of existing tools (Newton et al. 2013), resulted in sets of possibilities for four key attributes of the system, namely visualisation options, precinct typology options, assessment options and workflow options.

Workshops occurred during the 'generative' stage of system development, where the already refined design options were commented on by respondents. - see Figure 5. In accordance with Co-Design methodologies, and it's focus on end-user response to artefacts, the benefits of presenting a variety of discrete options were to prevent users from exploring the 'universe' of possibilities and thus maintaining focus during the design process. The next phase of Co-Design will see end-users engaged to evaluate the design prototypes that flow from the generate phase. This will be followed by post-design and as this will then iterate back through the Co-Design research framework for Prototype II and III.

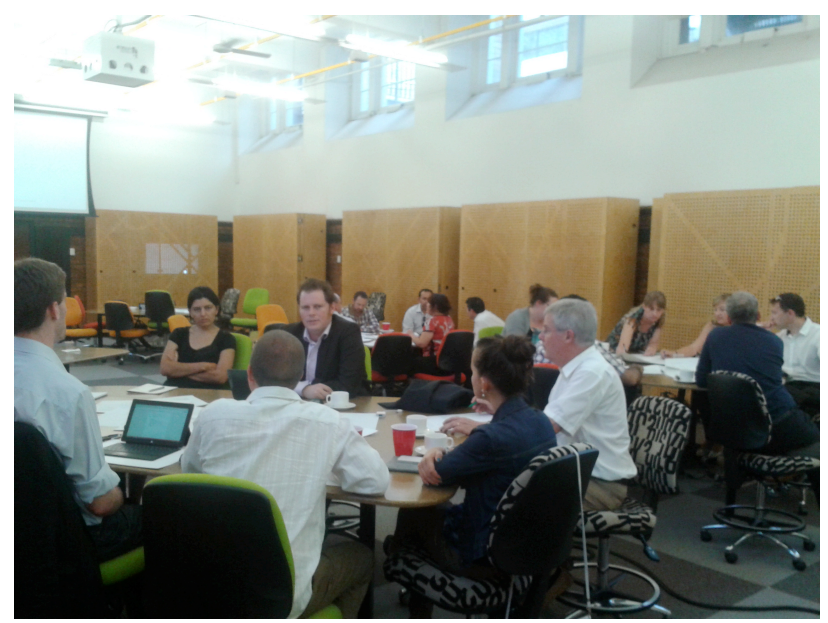

Figure 5: Workshop focused on the Co-design 'generative' stage of the precinct tool development

While the workshops provided a wealth of information, the nature of the workshops did not allow for some topics to be explored in detail. For this reason a number of semi-structured expert interviews were conducted with urban designers, land developers and architects, during which more detailed discussions were had around the ESP workflow, the detail of the precinct object library, how financial viability of projects is established and how the interviewees as potential end-users could see themselves using the tool in their regular business practice. Notes were also taken during these interviews and added to the tabulated notes from the workshops.

\subsection{Precinct Tool Development}

Precinct planning tools can be characterised as spatial information systems that visualise/calculate/estimate/predict how the characteristic features of a precinct design are expected to perform once constructed and occupied. These features can be specific precinct objects (e.g. particular buildings), a class or group of precinct objects (e.g. all apartment buildings) or the entire precinct itself.

The ESP precinct planning tool in this project is developed as an online open source tool. The tool will offer users a means to redesign a residential precinct in a $3 \mathrm{D}$ construct, receive feedback on the performance of a design, and compare the performance of various scenarios with 'business as usual' development trends.

Given ESP's broad range of potential end user perspectives and the impracticality of satisfying everyone's requirements, an Agile development strategy underpinning the Co-design prototyping approach was the natural choice. From the workshops, some common views were collected (detailed in the next section) which provided a skeleton from which to hang more detailed requirements. Instead of waiting for a formal requirements specification (or even a complete design) the development team could begin the implementation and testing of the system components that were most certain (e.g. the clientserver architecture, generic database schema and model evaluation, WebGL 3D rendering) and start preparing alternative prototypes of features that were uncertain and would predictably require scientific validation and end-user interaction testing (e.g. detailed mechanics of the user workflow interaction).

It has been found that some technologies are generally effective for supporting this kind of approach. A Web-based product with a public URL eliminates much of the friction of gaining feedback from end users. Emphasising loosely-coupled modular architectural design on both the client and server facilitates the testing and substitution of alternative feature implementations, as well as maximising re-use of components from existing systems (such as MUtopia). Behaviour-driven development (BDD) and testing is valuable for cooperation between programmers and researchers in defining the software verification criteria. These are not new ideas to professional software engineers, but they are quickly becoming nonnegotiable for all software development, research or otherwise, as the pace of competition increases.

Given the general direction in which the requirements for ESP are headed, the approximate architecture for this tool is illustrated in Figure 6. Despite its simplicity, such a design is sufficient to keep the developers busy until the detailed requirements begin to stabilise. 


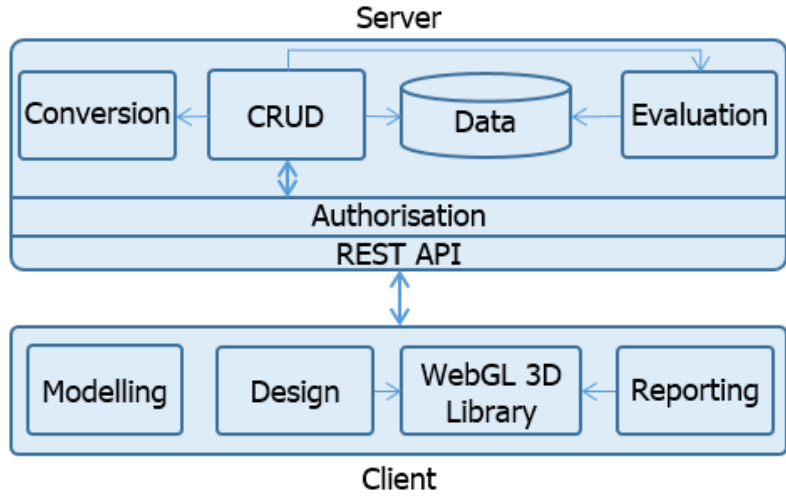

Figure 6: Initial draft of system architecture diagram.

\section{FINDINGS}

\subsection{Workshops \& Interviews}

Outputs from the workshop revealed a number of significant findings and these are summarised under the following six themes.

\section{Visualisation:}

While the research team initially identified realistic dwellings as being a requirement of the system, workshop attendees categorically stated that building massing was more than appropriate. This was based on the assumption that, as this was a sketching and evaluation tool, largely incapable of delivering the level of detail necessary to develop contextually appropriate dwellings for all urban locations, architects would be better employed to draft final renderings. It was also stated that, from prior interaction with the public, realistic representations can stall negotiations; as lay-people will assume that the visual object equates to the final built product. As such, simple massing, with setbacks and height limitations was more appropriate to this sketch design tool. However, while massing is suitable for doing preliminary assessments, a facility was also required for potentially 'inserting' more realistic CAD designs of prospective buildings and other precinct objects within the $3 \mathrm{D}$ volumetric representation as a basis for more realistic visualisations and assessments.

\section{Detail (of data):}

From this it was determined that housing typologies should provide the user with an appropriate level of detail, most probably deriving their settings from a rating system. However, should the user wish to alter the underlying data, or import existing models, they should be able to do so but only in an 'advanced' setting, based on specified input formats.

\section{Housing typologies:}

Similarly, housing typologies should be reasonably simple, in terms of the number of available options. End users should have a reasonably small number of available 'archetypal' dwellings and precinct objects to draw from, but have the ability to import more objects as required.

\section{Precinct performance indicators:}

The key output parameters were also a problematic aspect of the workshops, with each industry expert and government officer suggesting a range of key outputs motivated by their disciplinary, professional and 'leadership' perspectives. This was also the case with financial viability assessment approaches, with larger developers wanting a top-down model, sustainability experts suggesting life-cycle costings and social services experts commenting on the necessity of accommodating 'affordable housing' in the model. Based on these findings, as well as the time and cost limitations of the project, a series of key performance indicators, including water and energy use, traffic and congestion, carbon modelling and development cost were agreed upon to be the initial performance outputs - with more flowing from this after the next prototype iteration. Financial viability has been deferred to an industry expert for comment and validation.

\section{Workflow:}

The semi-structured interviews supported the findings from the workshops in that the renderings of the precinct objects should not be so detailed as to indicate a distinct style or design of a building to be positioned on an infill site at the early stages of precinct assessment. An option, however, to import more detailed building models was suggested for when projects are at the stage where some definitive designs have already been prepared by an architect, though this adds considerably to the time and expense of precinct planning. This Building Information Model (BIM) to Precinct Information Model (PIM) linkage is a critical challenge for contemporary precinct models (Newton et al 2013). In addition to the look of precinct objects, the manner in which they are placed in a precinct site was a primary focus of the semi-structured interviews. Some options that were discussed were a drag-and-drop approach as developed by Pettit et al. (2006) and the drawing and extruding of building footprints. These approaches can also be tedious in circumstances where rapid precinct scenarios need to be modelled or when a precinct may consist of hundreds of objects. An auto-populate option would be preferable or a situation where design and assessment could be done on land-use 'massings' to show context and then later designed in greater detail using some of the other approaches. These issues related to visualisation are something that can be resolved at later stages in the project. The Agile software development ensured that the first stages of software development could proceed without needing to have full resolution of the visualisation issues.

\section{End user groups:}

Other significant findings of the semi-structured interviews pertained to the general aspirations for end use of ESP. One interviewee mentioned their business practice was already using an existing design and assessment tool but noted that even after a couple of years of use a routine way of applying it to projects has not been established. Another interviewee could not suggest how their organisation might use the tool but gave the argument that having a distinct end-purpose in mind would mean the tool would be destined to fail. The alternative would be to provide the tool for use, tell the end users what it does, and then allow the end users to choose how to use it while taking feedback for improvement along the way. It was also highlighted that the research and development of ESP was setting an agenda for future best practice and the majority of current developers and local governments care very little about precinct performance, thus it may require state government mandate for use of a precinct sketch planning tool to enter into standard business practice. This is usual practice in planning innovation with leaders and laggards and there are indeed many developers already using a range of disparate precinct assessment and rating tools reviewed by Newton et al. (2013).

\subsection{Envision Scenario Planning - Prototype I}


While waiting on detailed requirements, the initial ESP prototype was primarily concerned with a rough implementation of the proposed workflow to gather feedback:

1. System Login

2. Select New or Existing Project

3. Select to Import a Precinct Boundary or Structure Plan or to Draw a New Boundary

4. Draw Precinct Boundary

5. Draw Precinct Roads and Paths

6. Select Precinct-Scale Technologies

7. Adjust Typology Options

8. Place Typology in Precinct

9. Generate Assessment Report (Figure 5)

10. Save Project

\section{Design \& Visualisation}

With the precinct boundary defined, the design process begins with the road network. For the prototype - and depending on the scale of the precinct - roads are rendered as a simple network of lines, with nodes at bends, corners and intersections. The user can drag and drop nodes to rearrange the road network, and add new lines and intersections to the network.

"Land uses" are the lots that fill the spaces between roads, and the buildings within them. Subdivision logic is used to ensure that each piece of land is allocated to exactly one land use with not gaps or overlaps (Figure 7). Land uses can be rendered as extruded footprints (with relative height set to any parameter value, including actual height) or as a $3 \mathrm{D}$ mesh for higher visual fidelity (Figure 8 ). The colours of the land uses can also be set on a spectrum based on their relative values for a parameter (Figure 3).

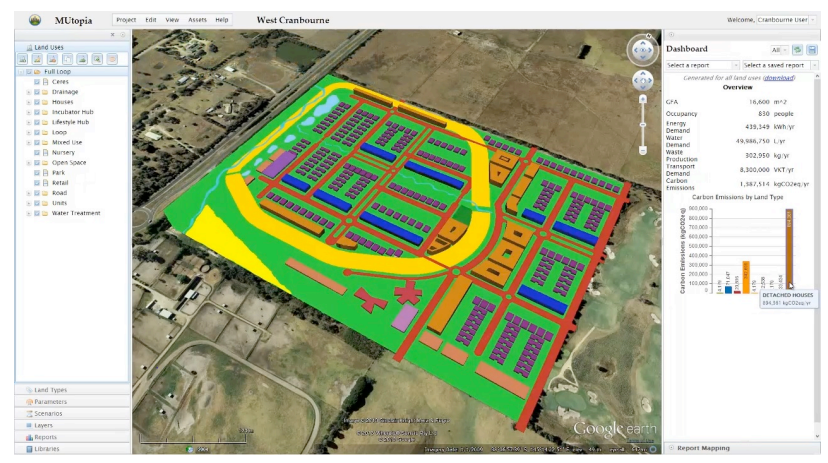

Figure 7: Prototype tool rendering of a large subdivided precinct.

\section{Assessment}

Outputs can be generated for a wide spectrum of themes and indicators, e.g. energy, Greenhouse gas (GHG) emissions, water consumption, Vehicle Kilometres Travel (VKT) and costs. Expected output modalities include simple text and numbers; pie, bar and line charts; and projecting output values onto land use colours and heights (Figures 3, 5, 6). Results can be downloaded in CSV format for more flexible analysis in Excel.

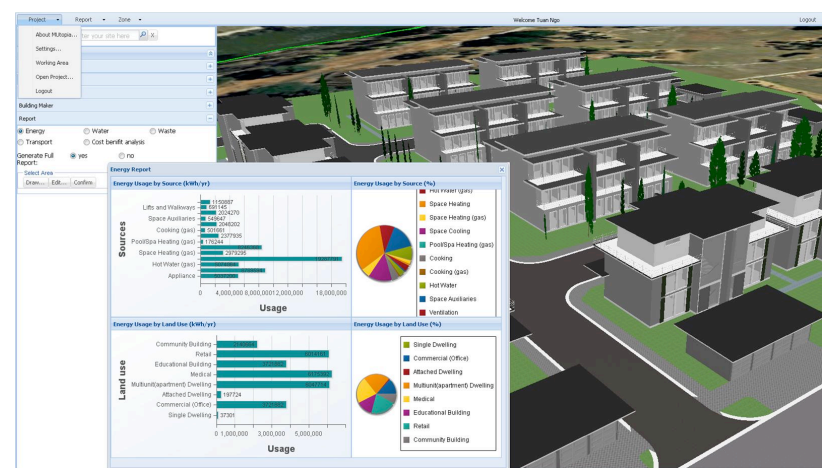

Figure 8: Prototype mesh rendering and reporting with charts.

\section{FUTURE WORK}

The next steps in the project are further iterations of workshops and interviews to validate and test the functionality and performance of the precinct planning tool. As indicated in Figure 2 there are two more prototype versions planned within a 1 year period to complete the first release of the tool. User testing and validation of the precinct planning tool will occur in case study locations, Melbourne and Perth. Once the co-design prototyping approach has run through the three iterations and the precinct software tool has been released the strengths and weaknesses of this approach will be fully accessed.

\section{CONCLUSIONS}

For rapid development of modern software systems, it is essential to be able to implement software development based on incomplete and evolving requirements, and to build on existing work to the fullest extent possible. This can greatly reduce the time required for development and testing for both the existing and new products. The Agile software development underpinning the Co-Design prototype approach provides a good way forward, but still requires experienced, patient project management and excellent communication between stakeholder groups.

Visualisation remains a contentious area to resolve but must be simple and non-representative of the final structure until detailed community engagement is needed. Results from the first iteration of the co-design prototyping approach indicate that end users prefer for early assessments to only be indicative of the maximum height and coverage of the proposed precinct. Likewise access to complex data should be hidden from the user (but available if required), allowing them to readily populate a precinct without having to enter large amounts of data. However, the level of 3D detail for presenting and supporting the precinct in more advanced stages of assessment still requires further testing with end users in the second and third iterations of the precinct planning design and implementation. Finally, financial viability should be as effective as possible, incorporating all fixed and variable costs (including development timelines) that one would expect to find in a realworld scenario.

\section{ACKNOWLEDGEMENTS}

The authors would like to acknowledge the funding support of the CRC for Spatial Information and the AURIN project made possible through the Australia Federal Government's Department of Education. 


\section{REFERENCES}

Beck, K., Beedle, M., Van Bennekum, A., Cockburn, A., Cunningham, W., Fowler, M., ... \& Thomas, D. (2001). Manifesto for agile software development.

Glackin, S. (2013) Redeveloping the Greyfields with ENVISION: Using Participatory Support Systems to Reduce Urban Sprawl in Australia, European Journal of Geography 3(1) 6-22.

Kwartler, M. \& Bernard, R. N. (2001). CommunityViz: an integrated planning support system. In: Brail, R. K. \& Klosterman, R. E. (eds.) Planning Support Systems: integrating geographic information systems and visualization tools Redlands, CA: ESRI Press, pp285-308.

Liamputtong, P. \& Ezzy, D. (2005). Qualitative Research Methods. 2nd ed. South Melbourne: Oxford University Press.

Murray, S. Bertram, N. Khor, L-A, Rowe, D. Meyer, B. Newton, P. Glackin, S. Alves, T. and McGauran, R. (2014). Processes for developing affordable and sustainable mediumdensity housing models for greyfield precincts. Melbourne: AHURI.

Newton, P. and Glackin, S. (2014) Understanding Infill: Towards New Policy and Practice for Urban Regeneration in the Established Suburbs of Australia's Cities, Urban Policy and Research DOI: 10.1080/08111146.2013.877389 Published online 3 March.

Newton, P. and Glackin S. (2013) Using Geo-spatial Technologies as Stakeholder Engagement Tools in Urban Planning and Development, Built Environment, 39(4), 480-508

Newton, P, Newman, P. Glackin, S. and Trubka. R. (2012). "Greening the Greyfields: Unlocking the Redevelopment Potential of the Middle Suburbs in Australian Cities" World Academy of Science Engineering and Technology no. 71. 65867.

Newton, P Marchant, D. Mitchell, J. Plume, J. Seo, S. Roggema, R. (2013). Performance Assessment of Urban Precinct Design: A Scoping Study, CRC-Low Carbon Living, Sydney, NSW, Australia.

Pettit, C. Cartwright, W. and Berry, M. (2006) Geographical Visualisation a Participatory Planning Support Tool for Imagining Landscape Futures, Applied GIS, 2(3): 22.1-22.17.

Pettit, C., Stimson, R., Tomko, M. and Sinnott, R. (2013a), Building an e-infrastructure to support urban and built environment research in Australia: a Lens-centric view, Proceedings of the Spatial Sciences and Surveying Conference 2013, Canberra, April.

Pettit, C. J., Klosterman, R. E., Nino-Ruiz, M., Widjaja, I. Tomko, M., Sinnott, R. and Stimson, R. (2013b), The online What if? planning support system, in S. Geertman, and J. Stillwell (Eds.), Planning Support Systems for Sustainable Urban Development, Springer Publishers, pp. 349-362.

Sanders, E., and Stappers, J.P.. (2014). "Probes, Toolkits and Prototypes: Three Approaches to Making in Codesigning." CoDesign: International Journal of CoCreation in Design and the Arts no. 10 (1):5-14.
Sanders, E. and Stappers, P.J. (2008). "Co-Creation and the New Landscapes of Design." CoDesign: International Journal of CoCreation in Design and the Arts no. 4 (1):5-18.

Seo, S., Tucker, S. and Newton, P. (2009), Automated Environmental Assessment of Buildings. In Newton P. Hampson K. and Drogemuller R (Eds). Technology Design and Process Innovation in the Built Environment, Spon Press, T\&F, London

Sinnott, R.O. C. Bayliss, A. Bromage, G. Galang, G. Grazioli, P. Greenwood, G. Macauley, D. Mannix, L. Morandini, M. NinoRuiz, C. Pettit, M. Tomko, M. Sarwar, R. Stimson, W. Voorsluys, I. Widjaj. (2014) The Australia Urban Research Gateway, Concurrency and Computation: Practice and Experience, DOI: $10.1002 / \mathrm{cpe} .3282$.

Strauss, A. and Corbin, J. (1988). Basics of Qualitative Research: Techniques and Processes for Developing Grounded Theory. 2nd ed. London: Sage. 